\title{
An Econometrics Analysis of the Impact of Agricultural Foreign Trade on Agricultural Development in Egypt
}

\section{Walaa Ali Mohamed ${ }^{1}$ and Eman Abd Elghafour Ahmed ${ }^{2}$}

${ }^{I}$ Department of Agricultural Economic, Faculty of Agriculture, Cairo University, Egypt.

${ }^{2}$ Department of Agricultural Economic, Agricultural and Biological Research Division, National Research Centre, 33 El Buhouth St., 12622 Dokki, Giza, Egypt.

Received: 20 Oct. 2019 / Accepted 10 Dec. 2019 / Publication date: 30 Dec. 2019

\begin{abstract}
This paper aims to measure the impact of agricultural foreign trade on agricultural development in Egypt through studying both: the agricultural development variables and agricultural foreign trade variables. Annual data covering the period (2000-2018) were used to estimate the impact of agricultural foreign trade on agricultural development in Egypt. Recursive Equations Model method was used in formulate standard model. The Two-Stage Least Squares method (2SLS) was used to estimate Simultaneous Equations Model, and it was found a positive relationship between AGDP and all of: agricultural investment, agricultural exports (at one year lagged) and agricultural imports. The results showed statistically significant positive relationship between Agricultural investments and Agricultural loans. While it found that agricultural exports have statistically significant positive relationship with Agricultural exports (at one year lagged). The positive relationship between agricultural imports and exchange rate has been confirmed. The results confirm the positive relationship between Agricultural labor force and both, Agricultural investments and Agricultural laborer wage.
\end{abstract}

Keywords: Gross domestic product, agricultural product, domestic investment, agricultural investment, agricultural labor force, Agricultural laborer wage, total loans, agricultural loans.

\section{Introduction}

The agricultural sector plays an important role to increase the rate of development through vertical and horizontal expansion in order to increase the incomes of farmers, on the other hand, to achieve comprehensive economic and social development in the country. Foreign trade plays a major role in achieving national economic goals, especially the achievement of the country's foreign exchange returns needs to finance the economic development plans and economic transformation programs, and rebalance the trade and agricultural balance. Therefore, one of the most important goals of the agricultural policy is to increase the agricultural exports and access new foreign markets, which leads to an increase in the trade flow between Egypt and international markets, through Agricultural development programs plans that increase agricultural productivity and production, and increase the quantities of agricultural commodities exporting to foreign markets.

\section{Research problem:}

The relationship between agricultural development and foreign agricultural trade is consider most importance in setting plans, policies and strategies that can be followed to increase the net return of agricultural foreign trade and increase rate of agricultural development. The imbalance in the trade and agricultural balance may have a negative impact on the economic growth performance and then on the performance of total and agricultural development, which necessitated studying the effect of agricultural foreign trade on the agricultural development performance in Egypt.

\section{Research objective:}

This research aims to measure the impact of agricultural foreign trade on agricultural development in Egypt through studying both: the agricultural development variables and agricultural foreign trade variables. Also, to formulate standard model for the relationship between agricultural development variables and agricultural foreign trade.

Corresponding Author: Walaa Ali Mohamed, Department of Agricultural Economy, Faculty of Agriculture, Cairo University, Egypt. E-mail: walaaali82@agr.cu.edu.eg 


\section{Data and measurement procedures:}

Annual data covering the period (2000-2018) were used to estimate the impact of agricultural foreign trade on agricultural development in Egypt. The data available in Ministry of Agriculture and Land Reclamation (MALR), and the Central Agency for Public Mobilization and Statistics (CAPMAS) were used, The Recursive Equations Model method was used in formulate standard model. The Two-Stage Least Squares method (2SLS) was used to estimate Simultaneous Equations Model.

\section{Theoretical Model:}

The Recursive Equations Model was used to describe the economic relations between the variables under study. Where the equations were divided into two main groups, the first group represents a sub-model with simultaneous equations, and the Tow -Stage Least Squares method was used to estimate the parameters of the simultaneous equations model for the first group, which consists of 4 Endogenous variables and 3 Exogenous variables. The second group represents another sub-model with equations in simultaneous equations, information of the coefficients of the Endogenous variables of the first group was used to determine the values of the exogenous variables of the second group, which consists of two equations that include two Endogenous variables and two exogenous variables.

\section{Methodology}

The model consists of a set of simultaneous equations with a mutual effect; equations were divided into behavioral equations and identification equations. Behavioral equations explain how a particular economic phenomenon responds to changes in another economic phenomenon, while identification equations are based on a specific basis for some of the variables used in the study.

The variable of Structural simultaneous equations model are divided into:

(a) Endogenous Variables: their balanced value is determined from within the model through mutual effects within the model, called determined variables.

(b) Predetermined Variables: that enter the formulating the model and have a predetermined value or are specified outside the model, and these variables are divided into:

1- Exogenous Variables: It is determined outside the model and is considered a form data.

2- Lagged Endogenous Variables: they are external (exogenous) variables because their value is predetermined from the previous period.

The model consists of four simultaneous equations that include four internal (endogenous) variables, which are the agricultural GDP, agricultural investments, agricultural exports, and agricultural imports. The model also includes three predetermined variables which are the exchange rate, agricultural exports in the previous year, and the value of agricultural loans. By applying order condition on the model it can be noted from the agricultural GDP equation that the number of internal and predetermined variables that did not appear in equation (E) equals the number of model equations (the number of internal variables of the model $(\mathrm{m})$ minus one), i.e. $\mathrm{E}=\mathrm{m}-1$, that means the agricultural GDP equation is Exact identify, as it was found that the agricultural investment equation and agricultural exports equation is also Exact identify. While it was found that the number of internal and predetermined variables that did not appear in equation (E) in the agricultural import equation is greater than the number of model equations minus one i.e. $\mathrm{E}>\mathrm{m}-1$, that is, the agricultural import equation is extremely identify than it should be. According the previous, it is possible to obtain for each of the three completely identified equations at least one specific value whose value differs from zero and then the behavioral model equations achieve degree and rank conditions of to use 2SLS.

\section{Model Specification}

In this section, the Recursive Equations Model used to explain the economic relations between the variables under study, where the equations were as follows.

$$
\begin{aligned}
Y_{1 t} & =F\left(Y_{2}, Y_{4}, X_{2}\right) \\
Y_{2 t} & =F\left(Y_{4}, X_{2}, X_{3}\right) \\
Y_{3 t} & =F\left(Y_{2}, X_{1}, X_{2}\right) \\
Y_{4 t} & =F\left(Y_{2}, X_{1}\right) \\
Y_{5 t} & =F\left(Y_{2}, Y_{6}\right)
\end{aligned}
$$




$$
\mathrm{Y}_{6 \mathrm{t}}=\mathrm{F}\left(\mathrm{Y}_{1}, \mathrm{Y}_{5}, \mathrm{X}_{2}\right)
$$

\section{First: Endogenous Variable}

$\mathrm{Y}_{1 \mathrm{t}}=$ value of agricultural GDP in billion L.E.

$\mathrm{Y}_{2 \mathrm{t}}=$ the value of agricultural investment in billion L.E.

$\mathrm{Y}_{3 \mathrm{t}}=$ The value of agricultural exports in the billion US\$.

$\mathrm{Y}_{4 \mathrm{t}}=$ value of agricultural imports in billion US\$.

$\mathrm{Y}_{5 \mathrm{t}}=$ Agricultural labor force in million.

$\mathrm{Y}_{6 \mathrm{t}}=$ Average annual wage of agricultural laborer in L.E/year.

$\mathrm{Y}_{7 \mathrm{t}}=$ the value of agricultural wages in billion L.E.

\section{Second: Exogenous Variable}

$\mathrm{X}_{1 \mathrm{t}}=$ the exchange rate of Egyptian pound against the dollar.

$\mathrm{X}_{2 \mathrm{t}}=$ the value of agricultural exports in the past year in billion US\$.

$\mathrm{X}_{3 \mathrm{t}}=$ the value of agricultural loans in billion L.E.

\section{Results and Discussion}

\section{Evolution of Total Economic Indicators}

Results in table (1) of applying simple regression analysis reveal that gross domestic production (GDP) followed a statistically significant increasing trend over the period 2000-2018, by L.E 230.7 billion at an annual growth rate of $13.9 \%$. As for agricultural gross domestic production (AGDP) representing $13.6 \%$ of GDP and results reveal that AGDP followed a statistically significant increasing trend by L.E 24.7 billion, at an annual rate of $12.2 \%$.

Table 1: Simple Regression Equations for Total Economic Indicators over 2000-2018.

\begin{tabular}{|c|c|c|c|c|c|}
\hline Indicators & Equation & $\mathbf{R}^{2}$ & $\mathbf{F}$ & Average & $\begin{array}{l}\text { \% Growth } \\
\text { Rate }\end{array}$ \\
\hline $\begin{array}{c}\text { Gross domestic production (GDP) } \\
\text { (L.E billion) }\end{array}$ & $\begin{aligned} & \hat{\mathrm{Y}}=651.1+ 230.7 \mathrm{X}_{\mathrm{i}} \\
&(9.63)^{*}\end{aligned}$ & 0.85 & $92.7^{*}$ & 1656.5 & 13.9 \\
\hline $\begin{array}{c}\text { Agricultural gross domestic } \\
\text { production (AGDP) (L.E billion) }\end{array}$ & $\begin{aligned} & \hat{Y}=43.8+ 24.7 X_{i} \\
&(9.06)^{*}\end{aligned}$ & 0.83 & $82.1^{*}$ & 203.1 & 12.2 \\
\hline Local Investment (L.E billion) & $\begin{array}{r}\hat{Y}=1.22+22.7 X_{i} \\
(13.1)^{*}\end{array}$ & 0.91 & $172.2 *$ & 225.6 & 10.1 \\
\hline $\begin{array}{c}\text { Agricultural investment (L.E } \\
\text { billion) }\end{array}$ & $\begin{array}{r}\hat{Y}=2.28+0.89 X_{i} \\
(4.18)^{*}\end{array}$ & 0.51 & $17.5^{*}$ & 11.2 & 8.0 \\
\hline Agricultural exports (US\$ billion) & $\begin{aligned} & \hat{Y}=0.35+ 0.16 X_{i} \\
&(7.6)^{*}\end{aligned}$ & 0.77 & $58.1^{*}$ & 1.97 & 8.2 \\
\hline Agricultural imports (L.E billion) & $\begin{aligned} & \hat{Y}=1.71+ 0.24 X_{i} \\
&(3.5)^{*}\end{aligned}$ & 0.42 & $12.2 *$ & 4.07 & 5.8 \\
\hline Exchange Rate (L.E /US\$) & $\begin{array}{c}\hat{Y}=1.93+0.53 X_{i} \\
(4.6)^{*}\end{array}$ & 0.56 & $21.2^{*}$ & 7.22 & 7.3 \\
\hline Total labor force (Million ) & $\begin{array}{r}\hat{Y}=15.52+0.69 X_{i} \\
(17.03)^{*}\end{array}$ & 0.95 & $290.0^{*}$ & 22.4 & 3.1 \\
\hline Agricultural labor force(Million ) & $\begin{array}{c}\hat{Y}=5.25+0.08 X_{i} \\
(3.7)^{*}\end{array}$ & 0.45 & $13.7^{*}$ & 6.09 & 1.4 \\
\hline $\begin{array}{c}\text { Agricultural laborer wage(L.E/ } \\
\text { laborer/ year) }\end{array}$ & $\begin{array}{r}\hat{Y}=1599.5+803.0 X_{i} \\
(5.64)^{*}\end{array}$ & 0.65 & $31.8 *$ & 6430 & 12.5 \\
\hline Agricultural wages(L.E billion) & $\begin{array}{r}\hat{Y}=11.9+5.17 X_{i} \\
(6.87)^{*}\end{array}$ & 0.74 & $47.2^{*}$ & 39.8 & 13.0 \\
\hline Total loans (L.E billion) & $\begin{array}{r}\hat{Y}=107.0+58.3 X_{i} \\
(5.2)^{*}\end{array}$ & 0.62 & $27.3 *$ & 476.0 & 12.2 \\
\hline Agricultural loans (L.E billion) & $\begin{array}{r}\hat{Y}=2.39+0.40 X_{i} \\
(3.61)^{*}\end{array}$ & 0.43 & $13.0^{*}$ & 6.35 & 6.3 \\
\hline
\end{tabular}

* Significance at 0.05 .

Source: Central Agency for Public Mobilization and Statistic (CAPMAS). - Egyptian Central Bank. 
Turning to Domestic investment, results presented in table (1) reveal that local investment followed a statistically significant increasing trend by L.E 22.7 billion, at an annual rate of $10.1 \%$. With regard to relative importance of Agricultural investments to total investment as seen in table (1), it can be noted that agricultural investment representing 5.3\% of total investment over the period 2000-2018 and results reveal that agricultural investment followed a statistically significant increasing trend by L.E 0.89 billion, at an annual rate of $8 \%$.

Table (1) presents evolution of Agricultural exports over the period (2000-2018), where as it can be noted that agricultural exports representing $10.5 \%$ of total exports and results reveal that agricultural exports followed a statistically significant increasing trend by US\$ 0.16 billion, at an annual rate of $8.2 \%$.

With regards to Agricultural imports as seen in table (1) the results reveal that relative importance of agricultural imports representing $10.1 \%$ of total imports, and agricultural imports followed a statistically significant increasing trend by US\$ 0.24 billion, at an annual rate of $5.8 \%$.

With regard to Exchange Rate, the results as seen in table (1) reveal that the exchange rate followed a statistically significant increasing trend by L.E 0.53 , at an annual rate of $7.3 \%$.

It is clear from Table (1) Total labor force followed a statistically significant increasing trend by 0.69 million worker, at an annual rate of $3.1 \%$.

Table (1) presents trends of Agricultural labor force over the period 2000-2018 where it can be noted that relative importance of agricultural labor force representing $27.4 \%$ of total labor force, and results reveal that agricultural labor force followed a statistically significant increasing trend by 0.08 million worker, at an annual rate of $1.4 \%$ over the period 2000-2018.

Table (1) presents Agricultural laborer wage where it followed a statistically significant increasing trend by $803 \mathrm{~L}$.E/ worker/ year, at an annual rate of $12.5 \%$ over the period 2000-2018.

Turning to the Agricultural wages, results presented in table (1) reveal that Agricultural wages followed a statistically significant increasing trend by L.E 5.2 billion, at an annual rate of $13 \%$.

The results of table (1) also showed that Total loans followed a statistically significant increasing trend by L.E 58.3 billion, at an annual rate of $12.2 \%$ over the period 2000-2018. As for Agricultural loans, the results showed in table (1) that Agricultural loans representing $1.6 \%$ of total loans over the period 2000-2018 and results reveal that agricultural loans followed a statistically significant increasing trend by L.E 0.39 billion, at an annual rate of $6.3 \%$.

\section{Standard Estimation of The relationship between agricultural development and foreign agricultural trade:}

The double logarithmic form is the best mathematical forms have been conducted to estimate the relationship. Table 2 shows the results obtained from regression function. The results show $1 \%$ increase in agricultural investments; agricultural exports (at one year lagged) and agricultural imports would result in statistically significant increasing in AGDP, by $0.74 \%, 0.22 \%$, and $0.52 \%$, respectively. As regard of agricultural investment, the result shows that $1 \%$ increasing in agricultural loans would result in statistically significant increasing in agricultural investment by $0.95 \%$, and model variables explain $64.5 \%$ in agricultural investment change, while the statistically significant change in agricultural exports and agricultural imports haven't been proven.

The results obtained from functional relationship as seen in table (2), show that $1 \%$ increase in agricultural exports (at one year lagged) would result in statistically significant increasing in agricultural exports by $0.89 \%$, and model variables explain $92.7 \%$ in agricultural exports change.

The imports function as show in table (2) reveal that a positive relationship between agricultural imports and exchange rate, where as $1 \%$ increasing in exchange rate would result in statistically significant increasing by $1.05 \%$ in agricultural imports, and exchange rate explain $24.1 \%$ of agricultural imports change.

Table (2) presents the positive relationship between Agricultural labor forces and both Agricultural investment and Agricultural laborer wage, where as $1 \%$ increasing in each of both would result in statistically significant increasing in agricultural labor forces by $0.38 \%$ and $0.31 \%$ respectively. Two variables explain $52.5 \%$ in agricultural labor forces. 
Table 2: Standard Estimation of The relationship between agricultural development and foreign agricultural trade over period (2000-2018).

\begin{tabular}{|c|c|c|c|c|}
\hline Indicators & Equation & $\mathbf{R}^{/ 2}$ & $\mathbf{F}$ & D.W \\
\hline $\begin{array}{l}\text { Agricultural gross } \\
\text { domestic production } \\
\text { (AGDP) }\end{array}$ & $\begin{array}{ccc}\log \hat{Y}_{1}=2.9+0.74 \log \hat{Y}_{2}+0.22 \log \hat{Y}_{4}+0.52 \log X_{2} \\
(10.9)^{*} & (1.91)^{*} & (5.66)^{*}\end{array}$ & 0.97 & $229.0^{*}$ & 1.5 \\
\hline Agricultural investment & $\begin{array}{c}\log \hat{Y}_{2}=0.83+0.22 \log \hat{Y}_{4}+0.18 \log X_{2}+0.95 \log X_{3} \\
(0.73) \quad(0.76) \quad(4.3)^{*} \\
\log \hat{Y}_{3}=0.23-0.25 \log \hat{Y}_{2}+0.26 \log X_{l}+0.89 \log \end{array}$ & 0.65 & $11.9^{*}$ & 1.6 \\
\hline Agricultural exports & $\begin{array}{llll}X_{2} & (-1.45) & (1.11) & (11.3)^{*}\end{array}$ & 0.93 & $76.7^{*}$ & 1.5 \\
\hline Agricultural imports & $\log \hat{Y}_{4}=\underset{(1.26)}{0.6+0.56 \log \hat{Y}_{2}+1.05 \log X_{I}}$ & 0.24 & $3.8^{*}$ & 1.4 \\
\hline Agricultural labor force & $\begin{aligned} \log \hat{Y}_{5} & =0.07+0.38 \log \hat{Y}_{5}+0.31 \log \hat{Y}_{6} \\
(3.61)^{*} & (4.18)^{*} \\
\log \hat{Y}_{6} & =3.45+1.36 \log \hat{Y}_{1}+0.93 \log \hat{Y}_{5}+0.38 \log \end{aligned}$ & 0.53 & $8.8^{*}$ & 1.5 \\
\hline Agricultural laborer wage & $X_{2}$ & 0.91 & $60.8^{*}$ & 1.4 \\
\hline
\end{tabular}

* Significance at 0.05 .

Source: Central Agency for Public Mobilization and Statistic (CAPMAS). - Egyptian Central Bank.

The results obtained from functional relationship as seen in table (2), show that $1 \%$ increase in AGDP would result in statistically significant increasing in agricultural laborer wage by $1.36 \%$, and model variables explain $90.9 \%$ in agricultural laborer wage.

\section{Summary and Recommendations}

This research aims to measure the impact of agricultural foreign trade on agricultural development in Egypt through studying both: the agricultural development variables and agricultural foreign trade variables. The Recursive Equations Model was used to describe the economic relations between the variables under study. It can be noted that all variables followed a statistically significant increasing trend over period (2000-2018), while the growth rates of all variables varied.

The results obtained from Recursive Equation Model reveal that positive relationship between AGDP and all of: agricultural investment, agricultural exports (at one year lagged) and agricultural imports. The results showed statistically significant positive relationship between Agricultural investments and Agricultural loans. While it found that agricultural exports have statistically significant positive relationship with Agricultural exports (at one year lagged). The positive relationship between agricultural imports and exchange rate has been confirmed. The results confirm the positive relationship between Agricultural labor force and both, Agricultural investments and Agricultural laborer wage.

In the light of the achieved results, the research offers the following recommendations:

- Devoting more attention to increasing agricultural investment because of its positive impact on agricultural exports, labor and agricultural wages.

- Dedicate efforts to increase financing agricultural activity through agricultural loans, due to its positive impact on agricultural investment and thus agricultural development.

- Increasing, diversifying and opening new markets for agricultural exports for their positive contribution to the development process.

\section{References}

Abdeljalil, H., 2012. Impact of exchange rate changes on the trade balance, case study of Algeria, Master's thesis, Faculty of Economics and Management Sciences, Department of International Finance, University of Abyeiba Belqaid, Algeria. 
Ahmed, A.H., et al., 1988. Economic and Social Analysis of Agricultural Employment and Its Problems in Egypt, Academy of Scientific Research and Technology in collaboration with the University of Alexandria.

Al-Dawi, A., 2016. The Impact of the Exchange Rate on Foreign Trade Study of the Case of Algeria( 1990-2014), Ph.D., Faculty of Economics, Business and Management Sciences, Department of Economic Sciences, University of Qasdi Marbah, Warqala, Algeria.

Dickey, D.A., and W.A. Fuller, 1979. Distribution of the estimators for Autoregressive time series: A unit root, Journal of the American Statistical Association, 74: 427-431.

Doha, S., 2015.The impact of exchange rate fluctuations on the trade balance and its remedies "Study of the Case of Algeria", Doctoral Thesis, Faculty of Economics, Business and Management Sciences, Department of Business Sciences, Mohamed Kheder University, Biskra, Algeria,

Http://www.capmas.gov.eg

Mamdouh, A.M., 2017. Impact of exchange rate change on total and agricultural foreign trade in Egypt - Journal of the Faculty of Agriculture, University of Manofieh, Shabin al-Kum, 2, October.

Mohamed, K., 2010. Quantitative assessment of the impact of the euro and the dollar on foreign trade (Case Study of Algeria), Doctoral Letter, University of Tlemcen, Algeria.

Oliver, H., 2001. Structural Vector Autoregressive Models and Monetary Policy Analysis, University of Berlin, Homepage: http://amor.rz.hu-berlin.de/ h32330ay, First version: June 2001, October.

Rania, M.A., 2015. Egyptian Agricultural Trade in the Framework of Sustainable Development, Ph.D., Department of Agricultural Economics, Faculty of Agriculture, Ain Shams University,

Saad, Z.N., et al., 2018. standard economic analysis of the relationship between agricultural development and agricultural foreign trade in Egypt, Egyptian Association for Agricultural Economics, Volume 28, Issue 2, June.

Saeed, A.A.A. and F.A. Mohammed, 2002. The relationship between the real exchange rate and real output in Egypt is a standard analytical study, Law Journal for Legal and Economic Research. 